\title{
Maternal death and near miss measurement: a case for implementation in developing countries in the sustainable development agenda, a review article.
}

\author{
Adeleke NA.
}

\begin{abstract}
"Ending preventable maternal mortality (EPMM) remains an unfinished agenda and one of the world's most critical challenges. Maternal health, well-being and survival must remain a central goal and investment priority in the sustainable development goal agenda". This statement from the World Health Organization (WHO) document Ending Preventable Maternal Death is most appropriate especially for developing nations.
\end{abstract}

Using 2010 as baseline, the current global maternal health targets are achievement of average maternal mortality ratio (MMR) of 70/100,000 live births. Nations whose MMR are more than 420/100,000 live births (the group where Nigeria belong) should have MMR not higher than 140 by 2030.

There was recognition of the need for improved measurement and data quality in other to track the progress or lack of it as we approach 2030. Maternal health services need to be accountable more than ever before. Maternal death and near miss measurement is one way to achieve this. In this paper a three levels of maternal death and near miss audit, surveillance and review is recommended for Nigeria and other developing nations. Both measurements can be done together.

Maternal death measurement also called maternal death review (MDR), audit or surveillance answers pertinent questions about the death of pregnant women, how many died? Where did they died? When did they died? Why did they died? Can these deaths be prevented? When MDR is followed by response (evidence base intervention) it becomes MDRS and thereby eliminates all preventable deaths. Every maternity service department and hospital, state and national government should audit the outcome of maternal health care being provided as a matter of accountability.

Correspondence Author: Adeleke NA. Email: najemdeen.adeleke@ uniosun.edu.ng

Department of obstetrics and gyneacology, College of Health Sciences. Osun state University Osogbo.

Research Journal of Health Sciences subscribed to terms and conditions of Open Access publication. Articles are distributed under the terms of Creative Commons Licence (CC BY-NC-ND 4.0). (http://creativecommons.org/licences/by-nc-nd/4.0).

http://dx.doi.org/10.4314/rejhs.v4i4.2 


\title{
Décès maternel et mesure de la quasi-disparition: un cas pour la mise en ouvre au pays en voie de developpement l'agenda des objectifs de développement durable.
}

\author{
Adeleke NA.
}

\begin{abstract}
Resume
"La fin de la mortalité maternelle évitable (EPMM) reste un programme inachevé et l'un des défis les plus importants au monde. La santé maternelle, le bien-être et la survie doivent rester un objectif central et une priorité d'investissement dans l'agenda des objectifs de développement durable ». Cette déclaration du document de l'Organisation Mondiale de la Santé (OMS) Mettant fin à la mort maternelle préventive est particulièrement appropriée, en particulier pour les pays en développement.
\end{abstract}

Si l'on tient compte de l'année 2010 comme base, les objectifs mondiaux actuels en matière de santé maternelle sont le taux moyen de mortalité maternelle (TMM) de 70/100 000 naissances vivantes. Les pays dont le TMM est supérieur à 420/100 000 naissances vivantes (groupe auquel appartient le Nigeria) devraient avoir un taux de mortalité infantile ne dépassant pas 140.

Nous avons reconnu la nécessité d'améliorer la mesure et la qualité des données dans d'autres pour suivre les progrès ou l'absence de celui-ci que nous approchons de 2030. Les services de santé maternelle doivent rendre des comptes plus que jamais auparavant. La mesure de la mortalité maternelle et de la quasidisparition est un moyen d'y parvenir. Dans le présent document, trois niveaux de vérification de la mortalité maternelle et de quasi-absence, la surveillance et l'examen sont recommandés pour le Nigéria et d'autres pays en développement. Les deux mesures peuvent être faites ensemble.

La mesure de la mortalité maternelle également appelée revue de la mortalité maternelle (MDR), la vérification ou la surveillance répond aux questions pertinentes sur le décès des femmes enceintes, combien sont morts? Où sont-ils morts? Quand sont-ils morts? Pourquoi sont-ils morts? Peut-on prévenir ces décès? Lorsque MDR est suivi par la réponse (intervention de base de la preuve), il devient MDRS et ainsi élimine tous les décès évitables. Tous les services de maternité et les hôpitaux, les États et les gouvernements nationaux devraient vérifier les résultats des soins fournis en tant que question de responsabilité.

Auteur correspondant: Adeleke NA.Email:najemdeen.adeleke@uniosun.edu.ng

Department of obstetrics and gyneacology, College of Health Sciences. Osun state University Osogbo. 


\section{INTRODUCTION}

Causes of maternal death across the globe are similar but different in their relative contribution. In developing nations heamorrhage, hypertensive disorders, infection, complication from abortion are common, while thrombo-embolism, heart disease and hypertension are the main determinants in developed nations $(1,2)$. It is important at this point to define various terminologies as regards maternal mortality and near miss and their measurement. Having a common understanding and applying uniform standard will improve metrics, measurement systems and data quality across different nations (3).

Maternal death: The death of a woman while pregnant or within 42 days of termination of pregnancy, irrespective of the duration and site of the pregnancy, from any cause related to or aggravated by the pregnancy or its management but not from accidental or incidental causes (4)

\section{Types:}

a) Direct maternal mortality: Maternal death due to obstetric complications or its management such as heamorrhage, eclampsia, prolong obstructed labour and anaemia etc.

b) Indirect maternal mortality: Maternal death resulting from diseases that predated or developed during pregnancy that was aggravated by the physiological effect of pregnancy such as Cardiac diseases and Diabetes Mellitus. etc.

c) Pregnancy-related death is defined as: The death of a woman while pregnant or within 42 days of termination of pregnancy, irrespective of the cause of death. e.g. road traffic accident, fall from a height or gun shut in pregnancy (4). This is otherwise called incidental causes.

d) Maternal mortality rate (MR): Is the number of maternal death per the population of women of reproductive age (15- 49 years) in a given area. MMRate $=$ Number of maternal deaths/Woman- year lived at ages 15- 49 (5)

e) Maternal mortality ratio (MMR): Is the number of maternal death expressed per100,000 live births (4). MMR= Number of maternal death/ Number live births in that year. This is used to measure and compare maternal health status all over the world.

f) Late maternal death: This is the death of a woman after 42 days up to 365 days or a year from the end of a pregnancy due to direct or indirect obstetrics causes (5).

g) Severe maternal outcomes (SMO): Maternal near misses and maternal deaths are referred to as severe maternal out comes (6).

h) Maternal death surveillance and response (MDSR) has been defined as a component of the health information system, which permits the identification, the notification, the quantification, and the determination of causes and avoidability of maternal deaths, for a defined time period and geographic location, with the goal of providing the measures necessary for its prevention (6).

i) Lifetime risk of maternal death: Refers to the probability that a 15 -yearold female will die eventually from a maternal cause if she experiences throughout her lifetime the risks of maternal death and the overall levels of fertility and mortality that are observed for a given population (4).

j) Proportion of maternal death (PM): This is the number of maternal death among all deaths of women of reproductive age. (15- 49 years) $\mathrm{PM}=$ Number of maternal deaths/ All female deaths at ages 15- 49. (4).

k) Severe acute maternal morbidity (SAMM), also known as 'near miss', has been defined by WHO technical working group as a woman who nearly died but survived a complication that occurred during pregnancy, childbirth or within 42 days of termination of pregnancy (7). The earliest group of workers on near miss, Mantel et al. defined near miss as if a woman has severe organ dysfunction or organ failure in pregnancy, during labour or in the puerperium that could result in maternal death, but she survives, she is described as having (SAMM) (8). Signs of organ dysfunction that follow lifethreatening conditions are used to identify maternal near misses so that the same classification of underlying causes is used for both maternal deaths and near misses $(7,8)$. 
However, the latest classification of maternal deaths according to WHO technical working group recognized three categories, namely, direct, indirect and unexpected complications (7).

All over the world MMR, MR, PM and MM life time risk are employed to measure maternal death. The measurement of SAMM is gradually gaining momentum. In 2012, a Cochrane Pregnancy and Childbirth Group review report concluded that "The necessity of recording the number and cause of deaths is not in question. Mortality rates are essential in identifying problems within the healthcare system. Maternal and perinatal death reviews should continue to be held, until further information is available. The evidence from serial data clearly suggests more benefit than harm. Feedback is essential in any audit system. The most effective mechanisms for this are unknown, but it must be directed at the relevant people (9). This conclusion was arrived at despite non-availability of any controlled trial of maternal mortality review.

Maternal death and near miss audit is a continuous action cycle designed to provide realtime, actionable data on maternal mortality and morbidity such as causes and contributing factors with a focus on using the findings to plan appropriate and effective preventive measures. It is a confidential process that builds on the existing system of disease surveillance to identify, notify and review all maternal deaths in the communities, health facilities (public and private) thus providing data-driven interventions that will reduce MM and near miss conditions. The impact of the interventions can be measured. Having MM and SAMM measurement in place is a step at achieving accountability for the reduction of maternal mortality in Nigeria and other developing countries $(10,11)$.

Simply put maternal death measurement is about counting every woman who died in the course of procreation, i.e. in the process of propagating human race. It is not a process for apportioning blame or shame the care giver but exists to identify the truth about every maternal death and learn lessons from the correctable factors that can save the lives of more mothers in future.

Death of a woman during pregnancy or soon after the end of a pregnancy constitutes a tragedy with terrible consequencies to the family, the community and the nation at large. In the family such an event traumatizes the psychic of the husband and the relatives. If a child is born through such a terminal pregnancy, the chance of survival of such a baby is compromised, and so is that of all other children under the age of five in such family. The community that experienced maternal death has lost one of its economically productive members and the national maternal mortality index is worsened with the death of every pregnant woman.

Despite the recognition of the usefulness of maternal death audit at enhancing safe motherhood it is disheartening that many countries in sub-Saharan Africa are yet to establish maternal mortality audit at national level. Nigeria only introduced a complicated maternal, perinatal audit (MPDRi) this year. This paper seeks to re-awaken the attention of the stakeholders in the area of maternal health to the urgent need for the implementation of a standalone maternal death and near miss review.

\section{METHODOLOGY}

This review on Maternal Mortality and Near miss measurement was produced after a search of literature on the subject. Pub med, African journal online AJOL, Cochrane review, paired review journals and WHO publications were assessed.

Two types of publication on maternal death and near miss were considered. First, reports on the magnitude and causes of maternal death mostly institution based and two, methodologies of measurement of maternal death and near miss, including the United Kingdom confidential enquiry into maternal death and its modification by WHO in Ghana and Indonesia.

Different methods of maternal death measurements, reviews, audits were discussed and recommendation for different health care settings and geographical area in Nigeria and other developing nations made.

\section{History of maternal deaths measurement/ audit.}

Pregnancy and delivery have being with man from pre-recorded time. While majority of child births are safe, it is true that some women lose their lives through pregnancy and childbirth, a process of procreation. In the same way that earliest child births were not recorded the accompanying maternal deaths of that time were also not documented. The arrival of modern medicine (referred to as western medicine) marked the beginning of changes. Anecdotal evidence pointed to the fact that management of labour and delivery probably started earlier than 
antenatal care. The history of Forceps delivery of Chamberlains period in the sixteenth century was older than the recorded time of Edinburgh obstetrician, John William Ballantyne, best known as the 'great apostle' of the antenatal care movement around the time of World War I (12$14)$.

Sweden led the world in effective maternal mortality reduction that dated back to eighteenth century and the only country with maternal mortality statistics in $18^{\text {th }}$ century Europe.(15) This was achieved by a combination of efforts, which included good coverage of skill birth attendant by trained midwives and medical supervision, use of aseptic techniques and strong political will (16.) However, these efforts came about by the realization from registrar general record of death that about 400 out of 651 maternal deaths were avoidable (16.) Maternal mortality ration in Sweden is about 6 per 100,000 live birth as at 1980 (15). Netherland, Denmark and Norway followed examples of Sweden.

Deaths in childbirth in England and Wales were first recorded by the Registrar General in 1847 (17). Great Britain and Northern Ireland maternal death Audit started in 1935 and it is singularly the most important step that has brought down maternal mortality ratio from 400 per 100,000 live births in nineteen thirties to 11 per 100,000 live births in 1999 (18).

The philosophy of Centre for Maternal and Child Enquiries (CMACE) is to recognise every maternal death as a young woman who died before her time and to use the lessons to save future mothers and babies $(19,20)$.

\section{Current maternal mortality profile}

Globally, the number of maternal deaths in 2010 was 287,000 per 100,000 live births and in 2013 it was 293,000 per 100,000 live births down from 377,000 in 1990 and 99\% of this occurred in developing nations $(21,22)$. Goal no 3 of the Sustainable Development Goals SDG is achievement of healthy lives and well being for all at all ages. The $1^{\text {st }}$ target of this goal is reducing MMR to 70 per 100,000 live births by 2030 (23).. A c c o r d i n g to t h e 2010 WHO/UNICEF/UNFPA/World Bank report on global, regional, and country maternal mortality ratio (MMR) estimates, while some countries have made substantial progress (such as Bhutan, Bolivia, China, Egypt, Equatorial Guinea, and Eritrea) others, mainly in sub-Saharan Africa (such as Chad and Zimbabwe) have made insufficient progress or none at all (22). At a country level, India had 56,000 or $19 \%$, Nigeria had 40,000 or $14 \%$ both countries accounted for roughly one third of the Global maternal deaths in 2010. Other countries with high maternal death are DR Congo, Pakistan, Sudan, Indonesia, Ethiopia, Tanzania and Bangladesh. UK, Canada, Estonia, Greece and Singapore all have low MMR (24).

In the United States, maternal death ratio was 17.8 per 100,000 in 2009 and 18.5 per 100,000 live births in 2013, (24). These MMR are too high for a developed nation. The nations with low MMR all have in place a method of measurement of maternal death, while USA like other nations with high MMR do not measure maternal death. High maternal mortality ratio is one of the features of under development and it is one of the social indexes with the widest gap between the rich and the poorer nations of the world (25).

As noted above, Nigeria is one of the countries with highest maternal mortality ratio in the world. National Demographic Health Survey reported 545 and 576 per 100,000 live birth in 2008 and 2013 respectivelly $(26,27)$. In 2008 report MMR in Osun state was 163 per 100,000. However, studies from secondary and tertiary institutions in the state recoded 214 and 1,713 per 100,000 live birth respectively $(28,29)$. In a six year (2008 to 2013) review of maternal mortality covering four states in which 121,808 deliveries were evaluated, the reported maternal mortality ratio were 2100,1380 , per 100,000 live births for Kano and Kaduna states respectively in 2008, these were reduced to 1070 and 360 for the two state respectively in 2011. The figures for FCT and Ondo were 240 and 180 per 100,000 live births respectively in the year 2013. Sadly, by the year 2013 MMR for Kano state had climbed to 2150 per 100,000 (30). This report and many others before it showed wide variations in MMR across different geopolitical zones of Nigeria as well as fluctuation that may occurred in the same place over time, this is a reflection of inequalities in maternal health, a common feature of maternal mortality in developing nations (31). Establishment of maternal mortality measurement could have prevented such worsening state of maternal health.

In Nigeria, proportional maternal mortality (PM) was $31.2 \%$ and $15.6 \%$ in 1990 and 2013 respectively (32). This depicts that death from pregnancy and child birth may be the most important killer of women in the reproductive age group in Nigeria. In Sweden 
proportional maternal mortality was $0.2 \%$ in 1980 (15).

Some of the quoted or referred MMR for Nigeria were obtained through surveys including National demographic and health survey. Survey by design can only measure pregnancy related death even with less accuracy but not maternal mortality. The MMR presented are therefore products of statistics from pregnancy related death captured in NDHS. Useful as they may be, the accuracy of demographic health survey and censures at measuring maternal mortality have been described as disappointing $(33,34)$.. This observation amongst others explained why developed nations such as U.K, Sweden, Netherlands, Finland have developed separate methods for measuring maternal mortality.

In developing countries maternal health service is funded by National Governments and financial and technical supports from development partners. WHO, UNFPA, CIDA, USAID and DFID referred to as donor agencies. Programmes such as Emergency Obstetric Care (EOC) and Post-abortion care, Live saving skills LSS, Prevention of maternal mortality PMM, making pregnancy safe initiative and women and child friendly initiative have all been implemented at various time (35).

These programmes were aimed at upgrading the skills of health care providers as well as improving infrastructural base of the facilities and supply of medical consumables. These measures need to be complimented by the establishment of maternal and near miss measurements.

In Sub-Saharan Africa, countries that have systematically introduced maternal death audits in the last decade include South Africa, Botswana, Malawi, and Ghana (36). Only a few nations among developing world such as South Africa, Egypt, Malaysia and Jamica have comprehensive maternal mortality review system (37).

\section{Challenges facing establishment of maternal death and near miss measurements.}

The obstacles facing universal operation of maternal mortality and near miss measurements can be categorized into two, challenges from within the provider (38) and from without, the former is far worse than the latter. Accountability is not necessarily a welcome concept, least of all by those in authority, public servants, or those who are perceived to be responsible for the welfare of a population or state including health care professionals (10).

The obstacles from within arose primarily from the health workers attitudes and practices as relate to accountability and documentation. Despite due emphasis given to detailed documentation during training of all categories of health professionals and the popular slogan of "what is not written down is not done", yet inadequate and lack of documentation of observations and procedures are common in medical case notes (38). Common excuses are heavy work load and working under pressure, which are not acceptable.

Accountability is a process that ensures the managers or authorities explained the actions taken, the reason for the action and accept judgment (responsibility) for the result of the actions. Simply put accountability as in audit is about telling the truth of the matter to all concerned. Good as it sound, the health professionals may not be favorably dispose to auditing in the care they provide. Many perceived accountability in the form of audit in the negative, as being indicting (10). This resistance must be overcome before a reliable maternal death and near miss audit can be instituted in any country, including Nigeria. Overcoming the fear require a legal safety net for health workers, the process must be confidential and anonymous. Findings from the audits cannot be used for litigation or administrative sanction. It has been observed that fear of litigation and lack of trust in confidentiality are responsible for failure to institute maternal mortality measurement in many countries $(39,41)$.

Human capacity and information communication technology ICT infrastructural challenges (most of the health facilities still use hard paper record keeping system) facing health serve delivery will also constitute obstacle to successful implementation of maternal death and near miss review.

Challenges from outside the health sector include socio- cultural factor of not wanting to talk about the dead (let the dead rest in peace), ignorance of the populace and poor financing of the health services. No method of measurement has zero cost. There is need for investment in strategies of measurement of maternal mortality and near miss adopted by any country (42). 


\section{Goal and objectives of maternal death and severe acute maternal morbidity measurements.}

The goal of the project is to eliminate all preventable maternal deaths everywhere in the world especially sub-Sahara Africa including Nigeria and avoid any woman developing acute severe complication that could have killed her (Near miss) situation.

Objectives: (adapted from MDSR WHO Publication 2013)

1. Identify all maternal deaths and near miss in the health facilities and communities through documentation, reporting and collation.

2. Review the conditions leading to maternal death and near miss.

3. Make a clinical diagnosis of cause/causes of maternal death and near miss.

4. Make a diagnosis of socio-economic and cultural circumstances leading to maternal death and near miss.

5. Establish and update continually maternal deaths and near miss data bank as well as maternal mortality ratio (MMR).

6. Develop, implement and evaluate intervention strategies (as a feed back) to eliminate all avoidable near miss and maternal deaths.

\section{Organization of Maternal Mortality and Near Miss Measurements.}

United Kingdom model of confidential enquiry on maternal death, reported every three year by Centre for maternal and child enquiry (CMACE) was accepted as gold standard. However, maternal mortality and near miss measurement actions are flexible and adaptable, based on the local circumstances such as man power, financial resources and area of coverage (health facility, community, local government, state and national). Measurement of near miss along with maternal death is an adaptation and a new concept (43). Similar modification of original United Kingdom pattern of confidential enquiries into maternal deaths had been carried out in Ghana and Indonesia (44). In Ghana positive factors (things that were done right in the management of the woman who eventually died) were recorded, while in Indonesia near misses conditions were included in the confidential enquiry into maternal death. In Ethopia MDSR publication, five different approaches were recommended namely, facility based audit, community maternal death audit by verbal autopsy or (sisterhood method), national confidential enquiry, near miss measurement and clinical facility audit (45). The fifth measurement strictly is not maternal mortality measurement as it is about assessment of the general quality of services provided by the health facility to it's clients.

In this review, three levels of maternal mortality and near miss measurements are recommended for Nigeria and other developing countries. These are level 1, Facility based near miss and maternal death audit. Level 2, state/regional maternal death and near miss audit and level 3, national maternal death and near miss surveillance and review MDSR. Facility MM and near miss measurement is the outcome audit of all cases of deaths during pregnancy, labour and pueperium and those women who almost died but survived in the hospitals. Nigeria near miss and maternal mortality study involving forty-four government owned hospitals across the country recently published in British Journal of Obstetric is an example of facility based maternal mortality and near miss (Level 1) measurement that was done on a national scale (46). This is only a component part but not a substitute for a confidential enquiry in to near miss and maternal mortality audit in Nigeria.

Level I MMR is carried out by reviewing case notes and interview of the care givers who participated in the management of the woman who died and those who had near miss. Information needed include but not limited to the following; bio-data, antenatal care, labour management, complication and treatment offered from time of presentation at the health facility till recovery for the near misses or death for the fatal cases. Background socio-economic information is also needed. Ethiopia facility maternal death audit form provide a good example of documentation required (45). This may be conducted monthly, quarterly or bi-annually depending on the number of cases. Level 1 MDR is to be implemented at public and private hospitals in Nigeria.

The management of the health facility (public or private) takes responsibility for the audit, while the head of the department of Obstetrics and Gynaecology or maternity unit is 
the principal investigator who is the chairman of the facility review committee. Other members of the committee are drawn from the team of care givers in the department and all the service units such as the laboratories (heamatology, chemical pathology e.t.c.) and radiological services including works department. Studies have reported that maternal deaths are not properly documented in the facilities and significant proportion of such deaths is avoidable $(38,41$, 47). Establishment of regular facility based maternal death and near miss measurement will change such practice of poor documentation and the lessons learnt from the exercise can generate relevant facility/local intervention strategy that can safe women lives $(3,7)$

"In level 2, both the facilities maternal deaths (level 1) and deaths in the communities are captured. Ondo state confidential enquiry into maternal death (CEMDOS) and Lagos state maternal death review MDR are examples of level 2 maternal death and near miss review" except that both did not include maternal deaths outside the health facilities. Fig. I.

The Ondo state programme started in 2010 and backed by the act of parliament, there is a system of tracking all maternal deaths, which are collated. There is a review committee of experts that review the collated cases and identified medical and other factors implicated in each death and recommends intervention to prevent a repeat. The state government has presented two reports of CEMDO that showed reduction in maternal mortality in the state. On account of which both WHO and Macarthur foundation commends the state and recommends the programme to developing nations. The success of CEMDO is good for Ondo State but it is not sufficient for Nigeria, just as it is not sufficient that many states including New Jersey have commenced regular maternal mortality review in the USA 50. However, lack of national programme of maternal mortality audit undermines the achievement.

The level 3 maternal death audit is when the entire population of the country such as Nigeria is covered a good example is the UK confidential enquiry in to maternal death.

The $2^{\text {nd }}$ and $3^{\text {rd }}$ levels measurements include maternal deaths in the facilities and communities at the geo-political area of coverage. This is contrary to and present a simpler alternative to the four levels of maternal death review contained in SOGON guideline 49.
This is so because, community maternal death audit which is the fourth in SOGON document is a part of audit at the state (levels 2) otherwise the latter will be mare aggregation maternal audits of health facilities in the state. (as Nigeria near miss and maternal mortality study earlier mentioned).

The Permanent secretaries in the ministry of health and hospitals management board are the responsible officers. The state chief epidemiologist is the principal investigator and the co-investigators are the disease surveillance officers in the state and local government director's primary health care as well as head of health facilities (both public and privates). The co-investigators are responsible for reporting of all cases of maternal deaths and near misses in their respective areas. There shall be a review committee of experts.

The $3^{\text {rd }}$ level of $\mathrm{MM}$ and near miss measurement covers the entire country and it is in the form of confidential enquiry or surveillance. It is organized as a collation or harvests of the $2^{\text {nd }}$ level measurement from across the states or regions. The epidemiological unit in the federal ministry of health should be responsible for the project, and a federal multi-disciplinary review committee of experts operates the programme.

For all the three levels of audits the trigger events are the occurrence of death of a woman of reproductive age (15-49 years) and severe pregnancy complication near miss. The actions include $(5,39)$.

(a) Identification and notification of all cases of the deaths of women in the age group 15 to 49 years using agreed format (including all known pregnant and those within 42 days of delivery anywhere it occurred) this is to be done within one week in health facilities and within fourteen days in the communities outside of health facilities.

(b) Review of all the deaths and near miss by the committee of experts, with a view to identify maternal deaths, determine medical and non-medical causes and recommends preventive actions to all concerned for immediate implementation.

(c) Periodic presentation of the aggregate reports and preventive measures for state wide adoption as well as monitoring the implementation and effectiveness (M \& E). Fig.I

(d) A fundamental principle of these 
approaches is the guarantee of confidentiality, usually anonymous, nonthreatening environment in which to describe and analyse the factors leading to adverse maternal outcomes. Ensuring confidentiality leads to openness in reporting which provides a more complete picture of the precise sequence of events.

(e) All Participants, including health workers, family members and the community members, should be assured that the sole purpose is to learn from the past tragedies and save lives in the future but not to apportion blames. The measurement seeks only to identify issues in maternal health seeking behaviors, associated factors and failures in the health care system. These are referred to as the obstetrics three delays 51,52 . While agreeing there is no single magical solution to reducing maternal mortality. The value of maternal mortality audit is proven and should be instituted both at local and national level 53.

Federal Ministry of Health inaugurated National Steering Committee to further develop the latest guidelines on Maternal Death Review to become Maternal and Perinatal Death Surveillance and Response (MPDSRi) on $10^{\text {th }}$ March 2015. This is the approach of some countries such as Tanzania and Bangladesh (54). This effort is commendable. However, this writer strongly feels it is not the right approach to solving the Nigeria high maternal and perinatal mortality and morbidity for the following reasons. The same Ministry of Health advised all the states in the federation to commence implementation of maternal death review in October 2013, at National Council of Health meeting. Many of the states are yet to comply; meaning the document of MDR is not yet tested before being reviewed. This suggests inconsistency in policy planning and implementation.

On the other hand the challenge of MDR combined with near miss is huge and deserves a dedicated program and the same is true of perinatal, neonatal and early infant mortality in the country. A successful maternal death and near miss measurement or review will impart positively on perinatal mortality, as a newly delivered woman who is in good state of health will practice exclusive breast feeding as appropriate, presents her child for immunization and implement personal as well as environmental hygiene as counseled in the ante-natal clinics. Perhaps the greatest obstacle to this new MPDSRi method is poor record keeping and unreliable data sources in the facilities, primary health centres, secondary facilities and local government health units. There is a need to rethink on this approach so as not to record failed programme in both maternal mortality review and perinatal death surveillance, a stitch in time saves nine, a properly implemented and successful MDR and a separate perinatal and neonatal death surveillance will serve Nigeria better at this level of our development as a nation.

\section{STAKEHOLDERS.}

G. Lewis in a review article titled the cultural environment behind successful maternal death and morbidity reviews identified three factors which are. 1) Individual responsibility and ownership. 2) A healthy institutional culture. 3) A supportive policy environment (55).

The following groups are the stakeholders in maternal death and near miss measurement 53. .They need to be involved at every stage of the project so as to engender acceptability and ownership by the community. The health Authority who is in position to act to bring about the needed changes must provide a conducive policy environment. The health professionals must all participate in the process through healthy institutional culture that promotes continuous learning organization.

1. Government agencies
i. Federal Ministry of Health (FMOH).
ii. State Ministry of Health (SMOH).
iii. Hospitals Management Board (HMB).
iv. Ministry of Women Affairs (M.O.W)
v. Local government authority LGA health authority

2. Legislature:

i. National assembly.

ii. State House of Assembly.

iii. Local government legislative council,

3. Health professional organizations.

4. The community and religious leaders.

5. Office of the $1^{\text {st }}$ lady.

6. Development Partners i.e.

i. United Nation Population Fund (UNFPA).

ii.Canadian International Development

Agency. (CIDA). 


\section{The role of governments: States and Federal.}

a. Enact the law to establish and guide maternal mortality and near miss measurement.

b. Constitute a review team of experts.

c. Make participation in the maternal mortality measurement compulsory for all health facilities public and privates.

d. Adequate and sustained funding.

\section{The committee of experts.}

This committee is a technical committee of mostly medical professionals. A typical review committee should comprise of the following professionals; a practicing Obstetrician and Gynaecologist of not less than 10 years post fellowship experience (The officer must be sufficiently senior to have acquired experience and to command the respect of others), other members will include Obstetrician Gynaecologists, Chief or Principal Medical officers, Anesthesiologist or Nurse anesthetist, Statistician, Chief Nursing Officer/midwife, Chief Laboratory Scientist, Chief Engineer Legal officer. e.t.c.

The functions of this committee include the following $(38,47)$.

I. Generate a reporting form/format for maternal death and near miss reporting.

II. Receive the reports of all cases of maternal death in the state no matter where they occurred.

III. Review all the cases of maternal deaths and report on the cause or causes (both medical and socioeconomic and cultural factors contributory factors) of death and near miss in each case.

IV. Recommend measures to prevent a recurrence of maternal death and near miss due to same factors that were identified.

V. Generate and keep data bank of maternal mortality ratio (MMR) and Near Miss.

VI. Monitor implementation of the recommendation in the facilities and the community.

VII. Any other function assigned to it by the state.

\section{PROCESS OF REPORTING MATERNAL} DEATH.

There shall be maternal mortality focal personnel (FP) in all health facilities providing maternity care. The medical director or most senior Medical Officer of all private health facilities shall serve as the focal person in private health facilities. The Director Primary Health for the local Government in collaboration with a community based FP in each town are the reporting officers for the communities in their LGA. The reports shall be forwarded within 7 days of its occurrence in the health facility and 14 days in the community.

\section{CONCLUSION}

Preventing avoidable maternal deaths and near miss can be achieved, even in Nigeria and other resource constrained countries of the world, but it requires the right kind of information on which to base effective interventions. Knowing the magnitude and geographical location of maternal mortality and near miss is good but this is not enough, we need to understand the underlying medical and socio-economic as well as cultural factors that led to the severe morbidity outcome.

Every maternal death and near miss has a story that can provide indications on practical ways of preventing further deaths as well as acute sever morbidity. This story must not be buried with the dead or locked up in the mind of the survivor of a near miss, maternal mortality and near miss measurement programme is the forum for this story, for the benefit of the living. This review advocates for the implementation of maternal death and near miss review/ surveillance (MDRS) in Nigeria as a standalone programme.

\section{REFERENCES}

1. Lale Say, Doris Chou, Alison Gemmill, Özge Tunçalp, Ann-Beth Moller, Jane Daniels, Metin Gülmezoglu A, Marleen Temmerman, Leontine Alkema. Global causes of maternal death: a WHO systematic analysis. Lancet Glob Health. 2014. 2: e323-33.

2. Yayla M: Maternal mortality in developing countries. J Perinat Med. 2003;31(5):386-91

3. WHO: Targets and Strategies for Ending Preventable Maternal Mortality EPMM. Human reproduction programme. hrp. research for impact. 2015.

4. World Health Organization. International classification of diseases (ICD) 10. Geneva, W H O . 1994 . A v a i l a b l e fromh.ttp://www.who.int/classification/icd/en /.

5. Federal Democratic Republic of Ethiopia Ministry of Health. Addis Ababa, Ethiopia. Maternal Death Surveillance and Response (MDSR) Technical Guideline. August, 2012.

6. John R. Wilmoth, Nobuko Mizoguchi, Mikkel 
Z. Oestergaard, Lale Say, Colin D. Mathers, Sarah Zureick-Brown, Mie Inoue, and Doris Chou A New Method for Deriving Global Estimates of Maternal Mortality. Stat Politics Policy. 2012; 3(2): 2151-7509.1038.

7. Robert Pattinson, Lale Say, João Paulo Souza, Nynke van den Broek, Cleone Rooney \& on behalf of the WHO Working Group on Maternal Mortality and Morbidity Classifications WHO maternal death and nearmiss classifications. Bulletin of the World Health Organization 2009;87:734-734. doi: 10.2471/BLT.09.071001

8. Mantel GD, Buchmann E, Rees H, Pattinson RC. Severe acute maternal morbidity: A pilot study of a definition for a near-miss. $\mathrm{Br} \mathrm{J}$ Obstet Gynaecol 1998; 105: 985-990.

9. Robert C Pattinson, Lale Say, JD Makin, Maria Helena Bastos . Critical incident audit and feedback to improve perinatal and maternal mortality and morbidity. Editorial Group: Cochrane Pregnancy and Childbirth Group Published Online: 19 OCT 2005. Assessed as up-to-date: 11 JAN 2011 DOI : 10.1002/14651858.CD002961.pub2

10. Julia Hussein and Friday Okonofua. Time for Action: Audit, Accountability and Confidential Enquiries into Maternal Deaths in Nigeria. Afr J Reprod Health 2012; 16[1]:9-145.

11. Althabe F, Bergel E, Cafferata ML, Gibbons L, Ciapponi A, Alemán A, Colantonio L, Palacios AR. Strategies for improving the quality of health care in maternal and child health in lowand middle-income countries: an overview of systematic reviews. Paediatr Perinat Epidemiol.2008; 22(Suppl 1):42-60.

12. Russell, Lesley. An Asclepiad family The Chamberlens and DeLaunes, 1569- 1792: Five generations of surgeons, physicians, accoucheurs and apothecaries. Journal of Medical Biography. Sage Publications. Prepublished Online 26 June 2014.

13. Gary Cunningham. Williams Obstetrics, 14th edition. Appleton-Century-Crofts, New York, NY, 1971, pages 1116-8.

14. John William Ballantyne. The making of antenatal life:Teratology and the clinic. Wellcome History winter 2009. 42(2). 1-24.

15. Ulf Hogberg and Showall(1986) Secular trends in maternal mortality in Sweden from 17501980. Bulletine of the world health organization who. 64(1):79-84. Vincent De Brouwere, Vincent De Brouwere, Rene Tonglet, Wim Van Lerberghe (1998). Strategies for reducing maternal mortality in developing countries: What can we learn from the history of industrialized west. Tropical medicine and international health.3(10): 771782.

16. Editoria : Maternal mortality: An historical audit .Journal of the Royal College of General Practitioners, 1984, 34 585-588.

17. World Health Organization. Beyond the numbers: reviewing maternal deaths and complications to make pregnancy safer. Geneva. 2004.

18. Centre for Maternal and Child Enquiries (CMACE). Saving Mothers' Lives: reviewing maternal deaths to make motherhood safer: 2006-08. The Eighth Report on Confidential Enquiries into Maternal Deaths in the United Kingdom. BJOG 2011;118(Suppl. 1):1-203.

19. Wikipedia. Confidential Enquiry into Maternal Deaths in the UK. The free encyclopedia. last modified $24^{\text {th }}$ November 2012.

20. WHO/UNICEF/UNFPA and The World Bank. Trends in Maternal Mortality: 1990-2010: Estimates developed by WHO,UNICEF, UNFPA and The World Basnk. Geneva, World Health Organization, 2012.

21. World Health Organization (WHO), UNICEF, UNFPA, and The World Bank, Trends in Maternal Mortality 1990-2008: Estimates Developed by WHO, UNICEF, UNFPA and The World Bank. Geneva: WHO, 2010. A v a i l a b l e a $\mathrm{t}$ www.who.int/reproductivehealth/publications /monitor-ing/9789241500265/en/index.html.

22. United Nations General Assembly, United Nations Sustainable Development Goals SDG.New York. United Nation Publication 2015: A/69/85;1-35.

23. World Health Organization. Trends in maternal mortality: 1990 to 2013. Estimates by WHO, UNICEF, UNFPA, The World Bank and the United Nations Population Division. Geneva: WHO; 2014 . Available from http://www.who.int/reproductivehealth/public ations/monitoring/maternal-mortality2013/en/ [cited 2014 Jul 18].

24. World Health Organization (WHO), Maternal Death Surveillance and Response. Technical Guidance. Information for action to prevent maternal death. WHO 2013.

25. National Population Commission (NPC) \{Nigeria\}and ICF Macro. 2009 Nigeria Demographic and Health Survey 2008 . Abuja, Nigeria. National population commission and ICF macro.

26. National Population Commission (NPC) \{Nigeria $\}$ and ICF International 2014. Nigeria Demographic and Health Survey 2013. Abuja, 
Nigeria. And Rockville, Maryland, USA: NPC and ICF International.

27. Adeleke NA Olowookere SA. Pattern of Maternal Mortality in a General Hospital Osogbo South Western Nigeria. Nig. Medical practitioner 2011. 59 (5-6): 68-75

28. Amatare Dinyain, G Olutoyin Omoniyi-Esan, Olaejirinde O Olaofe, Donatus Sabageh, Akinwumi O Komolafe, and Olusegun S Ojo. Autopsy-certified maternal mortality at Ile-Ife, Nigeria.Int J Womens Health.; 2014. 6: 41-46.

29. Galadanci H, Künzel W, Zinser R, Shittu O, Adams S, Gruhl M. Experiences of 6 years quality assurance in obstetrics in Nigeria - a critical review of results and obstacles. J Perinat Med. 2015. doi: 10.1515/jpm-20140302. [Epub ahead of print]

30. Betrán AP, Wojdyla D, Posner SF, Gülmezoglu AM (2005).National estimates for maternal mortality: an analysis based on the WHO systematic review of maternal mortality and morbidity. BMC Public Health. 2005 12;5:131

31. WHO, UNICEF, UNFPA, The World Bank, and United Nations Population Division Maternal Mortality Estimation Inter-Agency Group. Maternal mortality in 1990-2013 World population prospects: the 2012 revision. New York, Population Division, Department of Economic and Social Affairs, United Nations Secretariat, 2013.

32. Stanton C, Abderrahim N, Hill K. An assessment of DHS maternal mortality indicators. Stud Fam Plann 2000; 31: 111-23.

33. Gakidou E, Hogan M, Lopez AD. Adult mortality: time for a reappraisal. Int $J$ Epidemiol. 2004; 33: 710-7.

34. Adinma B-DJI, Adinma. ED A critic of maternal mortality reduction efforts in Nigeria. Trop. Jour. 2011. 28(1): 45-48.

35. Samuel Mills (HDNHE, World Bank). Maternal Death Audit as a Tool to reducing Maternal Mortality. HNPNotes. 2011.

36. Achem FF, Agboghoroma CC. Setting up facility-based maternal death reviews in Nigeria. BJOG 2014; 121 (Suppl. 4): 75-80.

37. Eugene J Kongnyuy and Nynke van den Broek. The difficulties of conducting maternal death reviews in Malawi. BMC Pregnancy and Childbirth 2008: 8(42) 1471-2393.

38. Cook R.The role of confidential enquiries in the reduction of maternal mortality and alternatives to this approach. Int $\mathbf{J}$ Gynaecol Obstet. $1989 ; 30(1): 41-5$.

39. Hussein J. Improving the use of confidential enquiries into maternal deaths in developing countries. Bull World Health Organ. 2007; 85(1): 68-69.

40. Thorsen VC, Johanne Sundby, Tarek Meguid and Address Malata. Easier said than done!: methodological challenges with conducting maternal death review research in Malawi. BMC Medical Research Methodology 2014,14:29.

41. Graham WJ, Ahmed S, Stanton C, Abou-Zahr C, Campbell OM. Measuring maternal mortality: an overview of opportunities and options for developing countries. BMC Med. 2008 May 26;6:12.

42. Graham W, Wagaarachchi P, Penney G, McCaw-Binns A, Antwi KY, Hall MH. Criteria for clinical audit of the quality of hospitalbased obstetric care in developing countries. Bull World Health Organ. 2000;78(5):614-20.

43. Hussein J, D'Ambruoso L, Armar-Klemesu M, Achadi E, Arhinful D, Izati Y, Ansong-Tornui J. Confidential inquiries into maternal deaths: modifications and adaptations in Ghana and Indonesia. Int J Gynaecol Obstet. 2009 ;106(1):80-4.

44. Samuel Hailu Fikre Enqueselassie Yemane Berhane. Health facility-based maternal death audit in Tigray, Ethiopia. Ethiop. J. Health Dev: 2009. 23(2): 115-119.

45. Oladapo OT, Adetoro OO, Ekele BA, Chama C, Etuk SJ, Aboyeji AP, et al. Nigeria Nearmiss and Maternal Death Surveillance Network. When getting there is not enough: a nationwide cross-sectional study of 998 maternal deaths and 1451 near-misses in public tertiary hospitals in a low-income country. BJOG 2015; 10.1111/1471-0528.13450

46. Ina May Gaskin, CPM, MA. Maternal Death in the United States: A Problem Solved or a Problem Ignored? J Perinat Educ. 2008; 17(2): 9-13.

47. Lawal Oyeneyin. Institutionalizing a Maternal Death Review System Case study of Ondo State Abiuye (Safe motherhood) Programme. Trop. J. Obstet. \& Gynaecol. 30 (suppl. 1), November 2013: S38.

48. www.sogon.org.ng Development diaries (2015) Nigeria: MacArthur Maternal Health Portfolio Accountability Baseline Report. Posted on May 1, 2015.

49. Maternal Mortality in New Jersey, 1999-2001. New Jersey department of health and senior services. 2005.

50. Thaddeus S and Maine D. "Too far to walk: maternal mortality in context," Social Science and Medicine. 1994. 38(8):1091-1110.

51. Barnes-Josiah D, Myntti C, Augustin A. The 
"three delays" as a framework for examining maternal mortality in Haiti. Soc Sci Med. 1998. 46(8):981-93.

52. Van Dillen J, Stekelenburg J, Schutte J, Walraven G, van Roosmalen J. The use of audit to identify maternal mortality in different settings: is it just a difference between the rich and the poor? Healthc Q. $2007 ; 10(2): 131-7$.

53. Lewis G. The cultural environment behind successful maternal death and morbidity reviews. BJOG. 2014: 121 (Suppl. 4): 24-31

54. Maternal Death Survillance and Review MDSR Action Network's newsletter! March 2015 edition. 


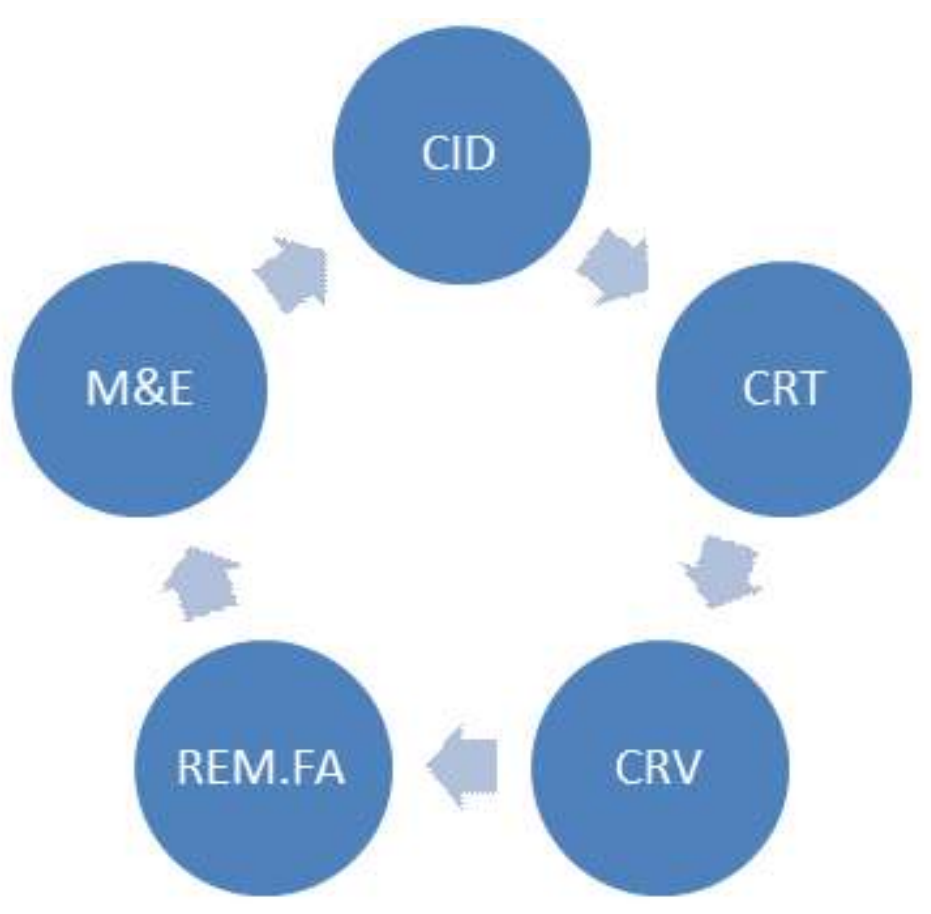

Figure 1: Maternal death and near miss action cycle

KEY:

$\mathrm{CID}=$ Case Identification.

CRT $=$ Case Reporting.

$\mathrm{CRV}=$ Case Review.

REM.FA= Recommendation For Action.

$\mathrm{M} \& \mathrm{E}=$ Monitoring and Evaulation.

Adapted from MDSR, WHO publication 2013. 
TABLE 1: Zonal and State status of implementation of materal death surveillance and review (MDSR) in Nigeria. as at December 2015.

\begin{tabular}{|c|c|c|}
\hline ZONES. & $\begin{array}{lll}\text { STATES } & \text { THAT } & \text { ARE }\end{array}$ & $\begin{array}{llll}\text { STATES } & \text { THAT } & \text { ARE } & \text { NOT }\end{array}$ \\
\hline & IMPLEMENTING MDSR. & IMPLEMENTING MDSR. \\
\hline NORTH WEST & NIL. & $\begin{array}{l}\text { KANO,KATSINA, JIGAWA } \\
\text { KADUNA,SOKOTO, } \\
\text { ZAMFARA, KEBBI. }\end{array}$ \\
\hline NORTH CENTRAL & NIL. & $\begin{array}{l}\text { KOGI, KWARA, PLATAEU, } \\
\text { NASARAWA, } \\
\text { BENUE, }\end{array}$ \\
\hline NORTH EAST & NIL. & $\begin{array}{l}\text { BAUCHI, BORNU, YOBE } \\
\text { ADAMAWA, TARABA, } \\
\text { GOMBE. }\end{array}$ \\
\hline SOUTH EAST & NIL. & $\begin{array}{l}\text { ABIA,EBONYI, IMO, } \\
\text { ENUGU, ANAMBRA. }\end{array}$ \\
\hline SOUTH SOUTH & NIL. & $\begin{array}{l}\text { AKWAIBOM, EDO, DELTA, } \\
\text { RIVERS, CROSS-RIVERS, } \\
\text { BALYESA, }\end{array}$ \\
\hline SOUTH WEST. & ONDO, LAGOS & EKITI, OGUN, OSUN,OYO. \\
\hline FCT & FCT. & NIL \\
\hline
\end{tabular}

